九州大学学術情報リポジトリ

Kyushu University Institutional Repository

Evaluation and Parametric Optimization of the Thermal Performance and Cost Effectiveness of Active-Indirect Solar Hot Water Plants

Kim, Young-Deuk

Faculty of Mechanical Engineering, Hanyang University

Thu, Kyaw

Faculty of Mechanical Engineering, National University of Singapore

$\mathrm{Ng}$, Kim Choon

Faculty of WDRC, King Abdullah University of Science and Technology

https://doi.org/10.5109/1544080

出版情報 : Evergreen. 2 (2)，pp.50-60，2015-09. Green Asia Education Center バージョン：

権利関係 : 


\title{
Evaluation and Parametric Optimization of the Thermal Performance and Cost Effectiveness of Active-Indirect Solar Hot Water Plants
}

\author{
Young-Deuk Kim ${ }^{1, *}$, Kyaw $\mathrm{Thu}^{2}$, Kim Choon $\mathrm{Ng}^{3}$ \\ ${ }^{1}$ Faculty of Mechanical Engineering, Hanyang University, Ansan, Republic of Korea \\ ${ }^{2}$ Faculty of Mechanical Engineering, National University of Singapore, Singapore \\ ${ }^{2}$ Faculty of WDRC, King Abdullah University of Science and Technology, Saudi Arabia \\ *Author to whom correspondence should be addressed, \\ E-mail: youngdeuk@hanyang.ac.kr
}

(Received August 27, 2015; accepted September 17, 2015)

\begin{abstract}
In the study, an investigation and comparison of the thermal performance and cost effectiveness of an active-indirect solar hot water plant (SHWP) at Incheon (Korea), Jeddah (Saudi Arabia) and Changi (Singapore) international airports are carried out. Plant performances are analyzed for various collector areas and storage tank volumes at the ASHRAE standard flow rate and are reported in terms of the annual solar fraction, solar thermal rating, as well as the capital payback period and annualized life cycle savings. The main objective of this study is to optimize a SHWP that supplies water at $65^{\circ} \mathrm{C}$ to a flight kitchen for the economic benefits for an average daily energy demand. For the energy demand of $100 \mathrm{~m}^{3} /$ day, the minimum payback periods of SHWPs at Incheon, Jeddah and Changi airports are 8.94 years with $A_{c}=1140 \mathrm{~m}^{2}$ and $V_{t}=32 \mathrm{~m}^{3}, 5.91$ years with $A_{c}=750 \mathrm{~m}^{2}$ and $V_{t}=24 \mathrm{~m}^{3}$ and 8.39 years with $A_{c}=1050 \mathrm{~m}^{2}$ and $V_{t}=28 \mathrm{~m}^{3}$, respectively.
\end{abstract}

Keywords: solar hot water system, simulation, economic evaluation, parametric optimization.

\section{Introduction}

Solar hot water systems have been recognized as the most cost-effective way of generating large amount of hot water for domestic, agricultural, commercial and industrial applications. A solar hot water system is environmental friendly as well as a creditable financial investment because it can significantly reduce fossil fuel burnings and consequent pollution and greenhouse gas emissions. Solar hot water systems can be used in most of the climate conditions as they employ the solar energy to produce useful heating. However, system costs vary considerably depending on geographic location, water usage and utility rates. To assure maximum cost benefit, therefore, the appropriate sizing of each component in the system and operating conditions are important parameters need to be accounted for.

A number of designs for solar hot water systems have been carried out using correlation (the $\phi$ method $^{1)}$, the generalized $\phi$ method $^{2)}$, the $\bar{\phi}$ method $^{3)}$, the $f$-chart method $^{4)}$, the $\bar{\phi}, f$-chart method ${ }^{5)}$, etc.) and simulation $\left(\right.$ MINSUN $^{6}$, SOLCHIPS $^{7}$, TRNSSYS ${ }^{8}$, WATSUN $^{9}$, etc.) based methods. Also, most of the previous optimization studies have been performed through optimizing an objective function, such as annual efficiency and solar fraction, annualized life cycle cost, life cycle savings, payback period, internal rate of return, etc. However, there is dearth of literature with respect to long-term thermal and economic analyses of a large solar hot water system.

Numerous previous studies highlighted that the selections of collector area and storage tank volume in a solar hot water plant (SHWP) are crucial factors for the plant performance. The present study is concerned with investigation and comparison of the thermal performance and cost effectiveness of SHWP at Incheon (Korea), Jeddah (Saudi Arabia) and Changi (Singapore) airports. Plant performances are analyzed for various collector areas and storage tank volumes at the ASHRAE standard flow rate and are reported in terms of the annual solar fraction, solar thermal rating, as well as the annualized life cycle savings and economic payback period. The primary objective is to optimize the long-term performance of an active-indirect solar hot water plant (SHWP), which supplies hot water at $65^{\circ} \mathrm{C}$ for use in a flight kitchen at each international airport. Using a proprietary simulation code, the detailed configuration of the SHWP in Korea, Saudi Arabia and Singapore is optimized to shorten the capital payback period. The performance evaluations are based on the simulations with the meteorological data (i.e., solar radiation and ambient temperature), evacuated-tube collector, seawater storage tank and plate heat exchanger models, which were developed in our previous works ${ }^{10,11)}$. 


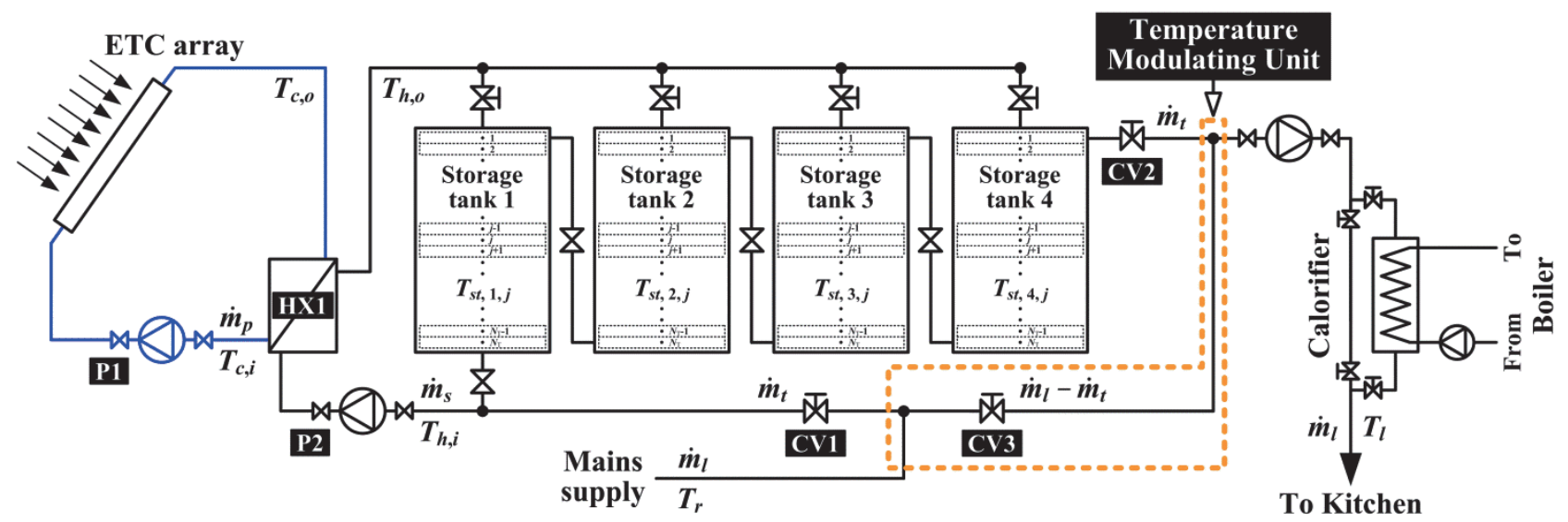

Fig. 1: A schematic diagram of the SHWP with a temperature modulating unit.

\section{Model description}

Fig. 1 shows a schematic diagram of the SHWP that supplies water at $65^{\circ} \mathrm{C}$ for the flight kitchen. The primary solar hot water circuit is connected to the four insulated storage tanks (secondary circuit) via a heat exchanger for hygiene and safety requirements. The four storage tanks are constructed in top-to-bottom arrangement achieving thermally stratification yet fulfill thermal demand of the load by supplying hot water. Cold makeup water is supplied to the mixing junction as soon as hot water from storage tank 4 is withdrawn for the load requirement. This arrangement assures that the storage tank is always fully filled. The water drawn from storage tank 1 is mixed at the mixing junction with cold makeup water, and then a mixture enters into heat exchanger. The water returning from heat exchanger supplies to the tank having temperature closest but less than that of the heat exchanger outlet water. This filling scheme ensures the tank 4 temperature to be the highest. A calorifier with a gas-fired boiler is used to meet temperature requirement of the load during nights and cloudy days. In the SHWP considered in this work, an additional supply component of cold makeup water is adapted to the calorifier. During the mid-day hours, the water temperature in the last tank is higher than the demand temperature. This water is mixed with the make-up water to attain the desired temperature. This arrangement enables some of high-stored energy during the midday hours to be used for the late-afternoon and night-time hours. The component models for the analysis of the SHWP include mainly: solar radiation, solar collector and storage tank. In the present work, a number of assumptions are made for the development of the models. It is assumed that the plant has well-insulated pipes with no leaks and its configuration and control are close to the ones considered in the development of the model. The flow distribution in the collectors is considered to be uniform.

\subsection{Solar radiation and ambient temperature model}

In the present work, the monthly average hourly global irradiance incident upon a tilted surface is estimated with several existing empirical theories, based on the 22-year average data of NASA Surface meteorology and Solar Energy $(\mathrm{SSE})^{12)}$. Here, the global irradiance consists of beam and diffuse components.

Based on the monthly average daily global radiation on a horizontal surface, the monthly average daily diffuse radiation is first calculated by means of a monthly average diffuse fraction correlation, as a function of monthly average clearness index and sunset (or sunrise) hour angle ${ }^{13)}$. The monthly average hourly diffuse and global radiations are then obtained from the monthly average daily diffuse and global radiations on a horizontal surface by using the ratio of hourly global to daily global radiation which is a function of the day length and the hour in question ${ }^{13,14)}$. Finally, the monthly average hourly global irradiation on a tilted surface is estimated using Hay-Davies-Klucher-Reindl (HDKR) anisotropic diffuse radiation model that considers the circumsolar diffuse and horizon brightening components on a tilted surface ${ }^{15-18)}$. Then, the global radiation on the tilted surface can be calculated as:

$$
\begin{aligned}
& I_{T}=\left(I_{b}+I_{d} A_{i}\right) R_{b}+I_{d}\left(1-A_{i}\right)\left(\frac{1+\cos \beta}{2}\right) \\
& {\left[1+f \sin ^{3}\left(\frac{\beta}{2}\right)\right]}
\end{aligned}
$$

where $A_{i}\left(=I_{b} / I_{o}\right)$ is an anisotropic index which is a function of the transmittance of the atmosphere for beam radiation, the geometric factor $R_{b}\left(=\cos \theta / \cos \theta_{z}\right)$ is the ratio of beam radiation on the tilted surface to that on a horizontal surface at any time and $f=\left(I_{b} / I_{h}\right)^{1 / 2}$.

The detailed procedure for estimating solar radiation incident on a tilted surface is discussed in our previous work $^{10,11)}$. The predicted monthly average hourly global radiations on a horizontal surface using the theories adopted in this study were substantiated based on the 10-year average data of Singapore Meteorological Service (SMS) at Changi international airport $\left(1^{\circ} 37^{\prime} \mathrm{N}\right.$, $103^{\circ} 98^{\prime} \mathrm{E}^{10)}$. Table 1 shows the monthly average daily global radiation on a horizontal surface $\left(\mathrm{MJ} / \mathrm{m}^{2} /\right.$ day $)$ of 
Table 1 Monthly average daily values of global solar radiation on a horizontal surface ${ }^{12)}$

\begin{tabular}{cccc}
\hline \multirow{2}{*}{ Months } & \multicolumn{3}{c}{ Global radiation, $H_{\mathrm{h}}\left(\mathrm{MJ} / \mathrm{m}^{2} /\right.$ day $)$} \\
\cline { 2 - 4 } & Incheon & Jeddah & Changi \\
\hline January & 10.01 & 16.31 & 16.13 \\
February & 13.10 & 19.15 & 18.79 \\
March & 16.31 & 22.25 & 18.18 \\
April & 19.33 & 24.77 & 17.53 \\
May & 19.94 & 25.81 & 16.45 \\
June & 18.25 & 25.63 & 15.88 \\
July & 15.23 & 25.34 & 15.48 \\
August & 16.31 & 23.51 & 15.59 \\
September & 15.08 & 22.21 & 16.31 \\
October & 12.89 & 20.02 & 16.45 \\
November & 9.68 & 16.52 & 15.62 \\
December & 8.78 & 14.94 & 14.65 \\
\hline Annual & \multirow{2}{*}{14.58} & 21.37 & 16.42 \\
(Average) & & & \\
\hline
\end{tabular}

the NASA SSE model ${ }^{12)}$. It is observed that the highest monthly average daily radiations at Incheon, Jeddah and Changi airports are $19.94 \mathrm{MJ} / \mathrm{m}^{2}, 25.81 \mathrm{MJ} / \mathrm{m}^{2}$ in May and $18.79 \mathrm{MJ} / \mathrm{m}^{2}$ in February, respectively, whilst the lowest monthly average daily solar radiations are found in December and have the values of $8.78 \mathrm{MJ} / \mathrm{m}^{2}, 14.94$ $\mathrm{MJ} / \mathrm{m}^{2}$ and $14.65 \mathrm{MJ} / \mathrm{m}^{2}$, respectively. The annual average daily radiations at each airport are $14.58 \mathrm{MJ} / \mathrm{m}^{2}$, $21.37 \mathrm{MJ} / \mathrm{m}^{2}$ and $16.42 \mathrm{MJ} / \mathrm{m}^{2}$, respectively.

The monthly average hourly ambient temperature is based on the measured data ${ }^{19)}$. For the simulation, the monthly average hourly meteorological data like irradiances and ambient temperatures are derived into polynomial and rational equations, respectively, which are expressed as a function of local time as follows:

$G_{b \text { or } d}=\sum_{i=0}^{L} a_{i} t^{i}, \quad T_{a}=\sum_{i=0}^{M} a_{i} t^{i} /\left(\sum_{i=0}^{N-1} b_{i} t^{i}+t^{N}\right)$

with $L=6$ and $M=N=3$. The coefficients ( $a$ and $b$ ) included in equation (2) are determined by using a conjugate gradient method $(\mathrm{CGM})^{20)}$. Figs. 2,3 and 4 show the monthly average hourly ambient temperature and the global irradiance on the tilted surface obtained from the aforementioned solar radiation model in Incheon, Jeddah and Changi, respectively. The maximum monthly average hourly ambient temperature and global irradiance are $29^{\circ} \mathrm{C}$ and $756 \mathrm{~W} / \mathrm{m}^{2}$ in Incheon, $38^{\circ} \mathrm{C}$ and $939 \mathrm{~W} / \mathrm{m}^{2}$ in Jeddah and $33^{\circ} \mathrm{C}$ and $736 \mathrm{~W} / \mathrm{m}^{2}$ in Changi, respectively.

\subsection{Solar collector model}

The collector efficiency can be defined as the ratio between the useful energy delivered over the aperture area and the total irradiance of the collector aperture ${ }^{21)}$. The efficiency curve provided by manufacturer is obtained from efficiency tests according to the standard $^{22)}$. Here, the efficiency curve is described after a second degree fit of efficiency points measured at different collector temperatures. However, since the
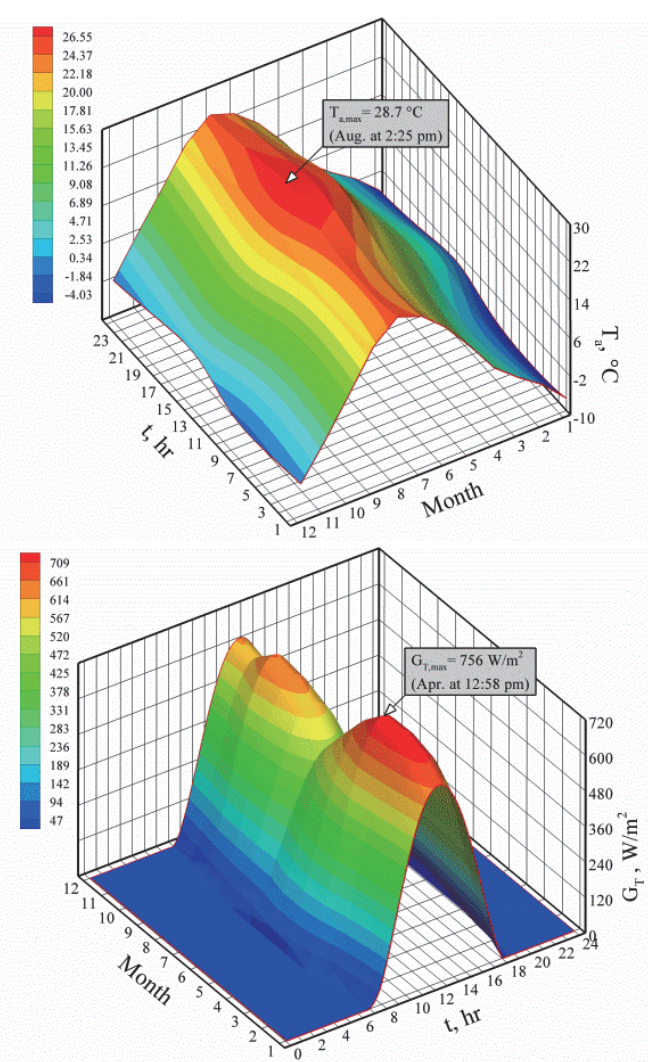

Fig. 2: Monthly average hourly (a) ambient temperature and (b) global irradiance on the tilted surface in Incheon, Korea.
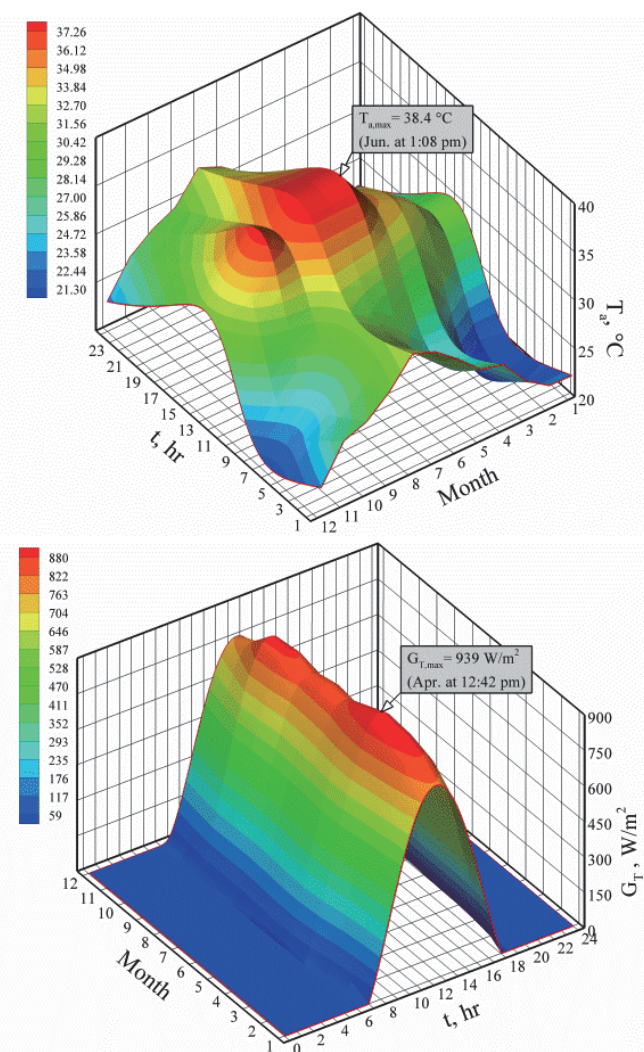

Fig. 3: Monthly average hourly (a) ambient temperature and (b) global irradiance on the tilted surface in Jeddah, Saudi Arabia. 


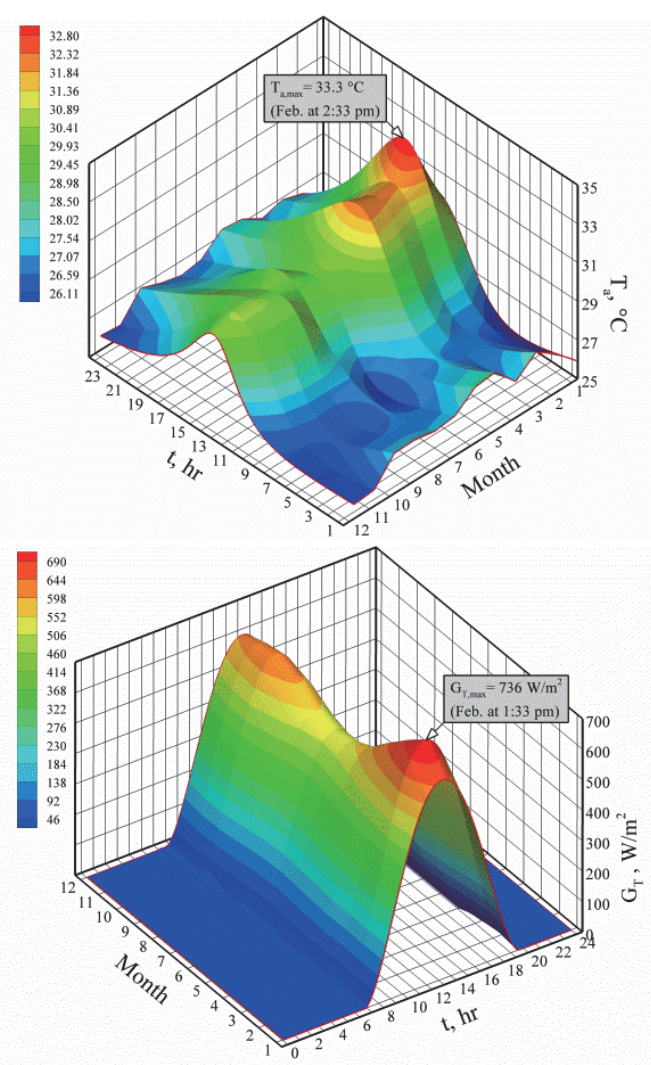

Fig. 4: Monthly average hourly (a) ambient temperature and (b) global irradiance on the tilted surface in Changi, Singapore.

efficiency curve is produced on the basis of normal incidence measurements, its use for different incident angles requires the correction of the optical efficiency, measured at normal incidence, by the appropriate incident angle modifiers for beam and diffuse irradiances. Thus, the collector efficiency at any incidence angle is determined as:

$$
\begin{aligned}
& \eta(\theta)=\eta_{0} K_{\theta b}(\theta)+\eta_{0} K_{\theta d}-c_{1} \frac{T_{m}-T_{a}}{G_{T}}- \\
& c_{2} G_{T}\left(\frac{T_{m}-T_{a}}{G_{T}}\right)^{2}
\end{aligned}
$$

with $K_{\theta b}(\theta)$ being a function of the incidence angle of the beam irradiance and the constant $K_{\theta d}$ for the diffuse irradiance. Here, $K_{\theta b}(\theta)$ can be approximated by the product of the transversal and longitudinal incidence angle modifiers ${ }^{23)}$.

From the definition of collector efficiency and equation (3), the collector outlet temperature can be calculated using following equation:

$$
\begin{aligned}
& \frac{q_{u}}{A_{a}}=\eta_{0} K_{\theta b}(\theta) G_{b}+\eta_{0} K_{\theta d} G_{d}-c_{1}\left(T_{m}-T_{a}\right)- \\
& c_{2}\left(T_{m}-T_{a}\right)^{2}-c_{3} \frac{d T_{m}}{d t}
\end{aligned}
$$

\subsection{Storage tank model}

A mathematical model for heat transfer in storage tank is based on the one-dimensional transient heat transport equation by convection and conduction along the prevailing flow direction of the storage tank. The multi-node model for the storage tank is employed to simulate the thermal stratification by dividing the tank into a specified number of tank segments. The longitudinal axis of the storage tank is assumed to be made up of $N$ disc shaped control volumes, each one having uniform temperature, as shown in Fig. 1. By considering the energy balance, which takes into account the convective and diffusive fluxes as well as the heat losses to the ambient within each control volume, a set of finite differential equations is established. The finite differential equation for the control volume $j$ of the storage tank $i$ gives:

$$
\begin{aligned}
& \rho_{i, j} c_{p, i, j} V_{t, i, j} \frac{T_{t, i, j}-T_{t, i, j}^{n}}{\Delta t}= \\
& Q_{c o n v, i n}^{i, j}-Q_{c o n v, o u t}^{i, j}+Q_{c o n d, i n}^{i, j}-Q_{c o n d, o u t}^{i, j}-Q_{\text {loss }}^{i, j}= \\
& \left\{\begin{array}{ll}
\left(\dot{m}_{s}-\dot{m}_{l}\right) c_{p, i, j-1} T_{t, i, j-1}, & \text { if } F_{i}^{\prime}=0 \\
\dot{m}_{l} c_{p, i, j+1} T_{t, i, j+1}, & \text { if } F_{i}^{\prime}=1
\end{array}\right\}- \\
& \left\{\begin{array}{ll}
\left(\dot{m}_{s}-\dot{m}_{l}\right) c_{p, i, j} T_{t, i, j}, & \text { if } F_{i}^{\prime}=0 \\
\dot{m}_{l} c_{p, i, j} T_{t, i, j}, & \text { if } F_{i}^{\prime}=1
\end{array}\right\}+ \\
& k A_{c s} \frac{T_{t, i, j}-T_{t, i, j-1}}{\Delta h}+k A_{c s} \frac{T_{t, i, j+1}-T_{t, i, j}}{\Delta h}-U_{t} A_{l}\left(T_{t, i, j}-T_{a}\right)
\end{aligned}
$$

where $\Delta t$ is the time step, $\Delta h$ is the grid spacing, and $n$ denotes value at previous time step.

The finite differential equations for the control volumes at the top $(j=1)$ and at the bottom $(j=N)$ of the storage tanks are different to the finite differential equation (5) for the internal control volumes because of the perturbation occurring at the ends of the tank due to inflow and outflow at each end. Therefore, it is assumed that any incoming mass of cold or hot water is fully mixed at the location of inlet. The finite differential equations for the control volumes at the top and bottom of the tank $i$ can be expressed as, respectively:

$$
\begin{aligned}
& \rho_{i, 1} c_{p, i, 1} V_{t, i, 1} \frac{T_{t, i, 1}-T_{t, i, 1}^{n}}{\Delta t}= \\
& Q_{c o n v}^{i, 1}+Q_{h x}^{i, 1}+Q_{n e t}^{i, 1}-Q_{c o n d}^{i, 1}-Q_{l o s s}^{i, 1}= \\
& \left\{\begin{array}{ll}
-\left(\dot{m}_{s}-\dot{m}_{l}\right) c_{p, i, 1} T_{t, i, 1}, & \text { if } F_{i}^{\prime}=0 \\
\dot{m}_{l} c_{p, i, 2} T_{t, i, 2}, & \text { if } F_{i}^{\prime}=1
\end{array}\right\}+F_{i} \dot{m}_{s} c_{p, h} T_{h, o}+ \\
& \begin{cases}\left(\dot{m}_{s}-\dot{m}_{l}\right)\left(1-F_{i}^{\prime}\right) c_{p, i+1, N} T_{t, i+1, N}- & \text { if } F_{i}=0 \\
F_{i}^{\prime} \dot{m}_{l} c_{p, i, 1} T_{t, i, 1}, & \text { if } F_{i}=1 \\
-\dot{m}_{l} c_{p, i, 1} T_{t, i, 1}, & \end{cases} \\
& k A_{c s} \frac{T_{t, i, 2}-T_{t, i, 1}}{\Delta h}-U_{t}\left(A_{c s}+A_{l}\right)\left(T_{t, i, 1}-T_{a}\right)
\end{aligned}
$$


$\rho_{i, N} c_{p, i, N} V_{t, i, N} \frac{T_{t, i, N}-T_{t, i, N}^{n}}{\Delta t}=$

$Q_{\text {conv }}^{i, N}+Q_{\text {net }}^{i, N}+Q_{\text {cond }}^{i, N}-Q_{\text {loss }}^{i, N}=$

$\left\{\begin{array}{ll}\left(\dot{m}_{s}-\dot{m}_{l}\right) c_{p, i, N-1} T_{t, i, N-1}, & \text { if } F_{i}^{\prime}=0 \\ -\dot{m}_{l} c_{p, i, N} T_{t, i, N}, & \text { if } F_{i}^{\prime}=1\end{array}\right\}+$

$\left\{\begin{array}{ll}-\left(\dot{m}_{s}-\dot{m}_{l}\right) c_{p, i, N} T_{t, i, N}, & \text { if } F_{i}^{\prime}=0 \\ \dot{m}_{l} c_{p, i-1,1} T_{t, i-1,1}, & \text { if } F_{i}^{\prime}=1\end{array}\right\}-$

$k A_{c s} \frac{T_{t, i, N}-T_{t, i, N-1}}{\Delta h}-U_{t}\left(A_{c s}+A_{l}\right)\left(T_{t, i, N}-T_{a}\right)$

where a control function $F_{i}$ that determines to which storage tank receives water from the heat exchanger is written as follows:

$F_{i}= \begin{cases}1, & \text { if } T_{h, o}<T_{t, i+1}, i=1 \\ 1, & \text { if } T_{t, i} \leq T_{h, o}<T_{t, i+1}, i=2,3 \\ 1, & \text { if } T_{h, o} \geq T_{t, i}, i=4 \\ 0, & \text { otherwise }\end{cases}$

The net flow between storage tanks depends on the magnitudes of the collector and load flow rates and the values of the control functions at any particular instant, and it can be determined with function $F_{i}{ }^{\prime}$

$$
F_{i}^{\prime}=\left\{\begin{array}{l}
0, \quad i=1 \\
\sum_{j=1}^{i-1} F_{j}, \quad i=2-4
\end{array}\right.
$$

It is noted that whenever the storage temperature is greater than the desired load temperature, the hot water mass flow rate withdrawn from the storage tank 4 is maintained constant by proportionately varying the discharge mass flow rate from the tank. On the other hand, whenever the storage tank 4 temperature falls below the desired load temperature, the maximum possible portions of the energy demand is met by keeping the discharge mass flow rate equals to the desired load flow rate and the rest of the energy demand is supplied by the auxiliary. A mixture with desired load temperature and flow rate is then produced by mixing with appropriate cold makeup water. Storage discharge flow rate and makeup water flow rate are determined by considering mass and energy balances at the mixing junction, as

$$
\begin{aligned}
& \dot{m}_{t}=\dot{m}_{l} \frac{c_{p, l r}\left(T_{l}-T_{r}\right)}{c_{p, t l}\left(T_{t, 4,1}-T_{l}\right)+c_{p, l r}\left(T_{l}-T_{r}\right)} \\
& \dot{m}_{r}=\dot{m}_{l} \frac{c_{p, t l}\left(T_{t, 4,1}-T_{l}\right)}{c_{p, t l}\left(T_{t, 4,1}-T_{l}\right)+c_{p, l r}\left(T_{l}-T_{r}\right)}
\end{aligned}
$$

Therefore, energy demand met by solar energy is calculated as,

$$
q_{s}=\dot{m}_{t} c_{p, t r}\left(T_{t, 4,1}-T_{r}\right)=\dot{m}_{l} c_{p, l r}\left(T_{l}-T_{r}\right)
$$

When the storage temperature is less than or equal to the desired load temperature, hot water from the storage tank is drawn at rate equal to that of the load. In such case, energy demand met by the solar energy is calculated as,

$$
q_{s}=\dot{m}_{l} c_{p, t r}\left(T_{t, 4,1}-T_{r}\right)
$$

When $T_{t, 4,1}<T_{l}$, the desired load temperature requirement can be met by an auxiliary energy. The required auxiliary energy is calculated as,

$q_{a}=\dot{m}_{l} c_{p, l t}\left(T_{l}-T_{t, 4,1}\right)$

The annual thermal performances of the plant, characterized by solar fraction and solar thermal rating, are defined as:

$$
\begin{aligned}
& S F=\frac{Q_{s}}{Q_{s}+Q_{a}}=\frac{\sum \int_{0}^{t} q_{s} d t}{\sum \int_{0}^{t} q_{s} d t+\sum \int_{0}^{t} q_{a} d t} \\
& E=\frac{Q_{l} \cdot S F}{A_{c}}
\end{aligned}
$$

where $Q_{l}$ is the desired hot water load over a year.

\subsection{Heat exchanger model}

The inlet temperature of flat plate heat exchanger in the secondary circuit is determined by considering mass and energy balance at the mixing junction of the water from the bottom of the storage tank 1 and the cold makeup water, as

$T_{h, i}=\frac{\left(\dot{m}_{s}-\dot{m}_{t}\right) c_{p, 1, N} T_{t, 1, N}+\dot{m}_{t} c_{p, r} T_{r}}{\left(\dot{m}_{s}-\dot{m}_{t}\right) c_{p, 1, N}+\dot{m}_{t} c_{p, r}}$

Using the inlet temperatures of the plate heat exchanger in primary and secondary circuits obtained from equations (3) and (17), both outlet temperatures are calculated by the effectiveness-number of transfer units (NTU) method. The effectiveness can be expressed as function of the number of transfer units, the heat capacity ratio, and the flow arrangement ${ }^{24)}$,

$\varepsilon=\frac{\exp \left[\left(1-C^{*}\right) \mathrm{NTU}\right]-1}{\exp \left[\left(1-C^{*}\right) \mathrm{NTU}\right]-C^{*}}$

where $C^{*}$ is the dimensionless heat capacity ratio.

Once the effectiveness value is given from equation (18), both outlet temperatures are obtained from the following effectiveness expression, defined as the ratio of the actual heat transfer rate for a heat exchanger to the maximum possible heat transfer rate,

$\varepsilon=\frac{C_{c}\left(T_{c, o}-T_{c, i}\right)}{C_{\min }\left(T_{c, o}-T_{h, i}\right)}=\frac{C_{h}\left(T_{h, o}-T_{h, i}\right)}{C_{\min }\left(T_{c, o}-T_{h, i}\right)}$

where $C_{c}$ and $C_{h}$ are the fluid heat capacity rate in primary and secondary circuit, respectively, and $C_{\min }$ is the minimum heat capacity rate.

\subsection{Economic evaluation model}

To balance the economic benefits of energy savings and capital investment, an economic objective function based on the payback period $(P B P)$ has been evaluated for the optimization. The total cost of a SHWP is simplified as collector area related cost $C_{D}$ and collector 
Table 2: Economic parameters adopted for economic evaluation.

\begin{tabular}{ll}
\hline Interest rate, $i(\%)$ & 5 \\
Inflation rate, $j(\%)$ & 2 \\
Fuel inflation rate, $e(\%)$ & 2 \\
Life cycle of plant, $n(\mathrm{yrs})$ & 15 \\
Collector cost coefficient, $C_{C}\left(\mathrm{US} \$ / \mathrm{m}^{2}\right)$ & 450 \\
Storage tank cost coefficient, & 1,500 \\
$C_{T}\left(\mathrm{US} \$ / \mathrm{m}^{3}\right)$ & \\
Instrumentation and control cost & $0.1 C_{\mathrm{C}}$ \\
coefficient, $C_{I C}\left(\mathrm{US} \$ / \mathrm{m}^{2}\right)$ & \\
Pump and support structure cost & $0.1 C_{\mathrm{C}}$ \\
coefficient, $C_{P S}\left(\mathrm{US} \$ / \mathrm{m}^{2}\right)$ & \\
Heat exchanger cost coefficient, & 320 \\
$C_{H X}\left(\mathrm{US} \$ / \mathrm{m}^{2}\right)$ & 395,000 \\
Boiler cost coefficient, $C_{B}(\mathrm{US} \$)$ & 0.1523 \\
Fuel cost coefficient, $C_{F}(\mathrm{US} \$ / \mathrm{kWh})$ & \\
\hline
\end{tabular}

area independent $\operatorname{cost} C_{I}$ :

$C_{S}=C_{D} A_{c}+C_{I}=$

$\left(C_{C}+C_{I C}+C_{P S}+C_{H X} C_{O}\right) A_{c}+\left(C_{T} V_{t}+C_{B}\right)=$

$\left(1.2 C_{C}+C_{H X} C_{O}\right) A_{c}+\left(C_{T} V_{t}+C_{B}\right)$

where $C_{O}=G_{T, \max } \eta_{0} / U_{H X}$ LMTD and the instrumentation and control and the pump and support structure costs, $C_{I C}$ and $C_{P S}$, for the plant has been taken as $10 \%$ of the collector cost. The capital recovery factor is calculated based on the following expression as:

$C_{R F}(i, n)=\frac{i(1+i)^{n}}{(1+i)^{n}-1}$

The effective interest rates are adapted to account for the general inflation rate $j$ and energy inflation rate $e$, respectively, with the interest rate $i$ and it can be expressed as:

$i^{\prime}=\frac{i-j}{1+j}, \quad i^{\prime \prime}=\frac{i-e}{1+e}$

Annualized life cycle saving $(A L C S)$ is the difference between the annual costs of a conventional plant and solar plant, and each annual cost is the sum of the annualized cost of the plant and the annual cost of auxiliary energy, which is represented by the following equation:

$$
A L C S=\left(C_{B}-C_{S}\right) C_{R F}\left(i^{\prime}, n\right)+S F \frac{Q_{l} C_{F}}{\eta_{\text {aux }}} \frac{C_{R F}\left(i^{\prime}, n\right)}{C_{R F}\left(i^{\prime \prime}, n\right)}
$$

The $P B P$ of the plant is expressed as follows:

$P B P=\frac{C_{S} C_{R F}\left(i^{\prime}, n\right) n}{A L C S}$

The cost coefficients for economic evaluation are given in Table 2 and applied equally to the simulations for fair comparison on the economic performance between different countries. It is noted that the cost coefficient for the storage tank is expressed in terms of its volume.
Table 3: Economic parameters adopted for economic evaluation.

\begin{tabular}{|c|c|c|}
\hline \multirow{2}{*}{ Incheon, Korea } & Latitude, $\phi\left({ }^{\circ} \mathrm{N}\right)$ & 37.45 \\
\hline & Longitude, $L_{l o c}\left({ }^{\circ} \mathrm{E}\right)$ & 126.45 \\
\hline \multirow{2}{*}{ Jeddah, Saudi Arabia } & Latitude, $\phi\left({ }^{\circ} \mathrm{N}\right)$ & 21.67 \\
\hline & Longitude, $L_{l o c}\left({ }^{\circ} \mathrm{E}\right)$ & 39.15 \\
\hline \multirow{2}{*}{ Changi, Singapore } & Latitude, $\phi\left({ }^{\circ} \mathrm{N}\right)$ & 1.36 \\
\hline & Longitude, $L_{l o c}\left({ }^{\circ} \mathrm{E}\right)$ & 103.99 \\
\hline \multicolumn{2}{|c|}{ Hot water demand temperature, $T_{l}\left({ }^{\circ} \mathrm{C}\right)$} & 65 \\
\hline \multicolumn{2}{|c|}{ Makeup water temperature, $T_{r}\left({ }^{\circ} \mathrm{C}\right)$} & 28 \\
\hline \multicolumn{2}{|c|}{ Daily hot water load, $V_{l}\left(\mathrm{~m}^{3} /\right.$ day $)$} & 100 \\
\hline \multicolumn{3}{|c|}{ Evacuated tubular collector, Thermomax Ltd. } \\
\hline \multicolumn{2}{|c|}{ Aperture area per collector, $A_{a}\left(\mathrm{~m}^{2}\right)$} & 3.229 \\
\hline \multicolumn{2}{|c|}{ Number of tubes per collector } & 30 \\
\hline \multicolumn{2}{|c|}{ Number of collectors in series } & 1 \\
\hline \multicolumn{2}{|l|}{ Optical efficiency, $\eta_{0}$} & 0.727 \\
\hline \multicolumn{2}{|c|}{ Global heat loss coefficient, $c_{1}\left(\mathrm{~W} / \mathrm{m}^{20} \mathrm{C}\right)$} & 0.85 \\
\hline \multicolumn{2}{|c|}{$\begin{array}{l}\text { Temperature dependence of global heat loss } \\
\text { coefficient, } c_{2}\left(\mathrm{~W} / \mathrm{m}^{2 o} \mathrm{C}^{2}\right)\end{array}$} & 0.0093 \\
\hline \multicolumn{2}{|c|}{ Effective thermal capacity, $c_{3}\left(\mathrm{~kJ} / \mathrm{m}^{2} \mathrm{~K}\right)$} & 4.2 \\
\hline \multicolumn{2}{|c|}{ Minimum tilt angle, $\beta\left(^{\circ}\right)$} & 20 \\
\hline \multicolumn{2}{|c|}{ Recommended optimum tilt angle, $\beta_{\text {opt }}\left({ }^{\circ}\right)$} & $0.7 \phi$ \\
\hline \multicolumn{2}{|l|}{ Azimuth angle, $\gamma\left({ }^{\circ}\right)$} & 0 \\
\hline \multicolumn{2}{|c|}{$\begin{array}{l}\text { Mass flow rate per unit area of collector, } \\
G\left(\mathrm{~kg} / \mathrm{m}^{2} \mathrm{~s}\right)\end{array}$} & 0.02 \\
\hline \multicolumn{3}{|c|}{ Cylindrical, well mixed, always full, with $(H / D)=2$} \\
\hline \multicolumn{2}{|c|}{ Heat loss coefficient, $U\left(\mathrm{~W} / \mathrm{m}^{2 o} \mathrm{C}\right)$} & 1.5 \\
\hline \multicolumn{2}{|c|}{ Plate heat exchanger effectiveness, $\varepsilon$} & 0.7 \\
\hline \multicolumn{2}{|l|}{ Boiler efficiency, $\eta_{a u x}$} & 0.75 \\
\hline
\end{tabular}

\subsection{Numerical solution}

The fully implicit finite differential equation (5) for the internal control volumes is solved in conjunction with the boundary conditions given by equations (6) and (7) using a standard tridiagonal matrix algorithm (TDMA) with a successive line under-relaxation method, while a shooting method is used to solve equations (4) and (19) for the outlet temperatures of the collector and the plate heat exchanger in primary and secondary circuits, respectively. For the initial conditions of the problem, it is assumed that the entire system is in thermal equilibrium with the ambient. For the simulations, the time and space steps are chosen to give a stable solution and grid independent results and its values used in this study are $\Delta t=300 \mathrm{sec}$ and $\Delta h=0.1 \mathrm{~m}$, because higher values of $\Delta h$ leads to a considerable under-prediction of the energy input into the storage tank and the delivered energy. The convergence criterion for the time step is $\left|s^{m+1}-s^{m}\right|<10^{-4}$, where $s$ is any variable $\left(T_{c}, T_{h}, T_{t}\right)$, and $m$ is the iteration level.

The plant parameters and input data are given in Table 3. Single collector array in series arrangement is adapted for low pressure drop and high collector efficiency purposes. A typical hourly distribution of hot water consumption for a day is presented in Fig. $5^{25}$. 


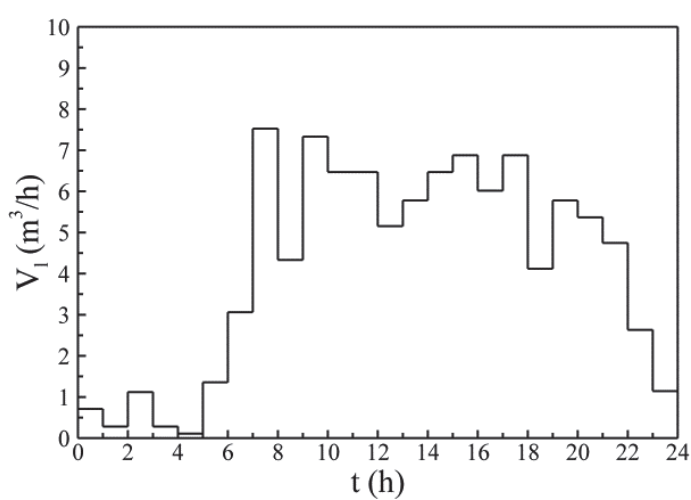

Fig. 5: Daily hot water consumption profile ${ }^{25)}$.
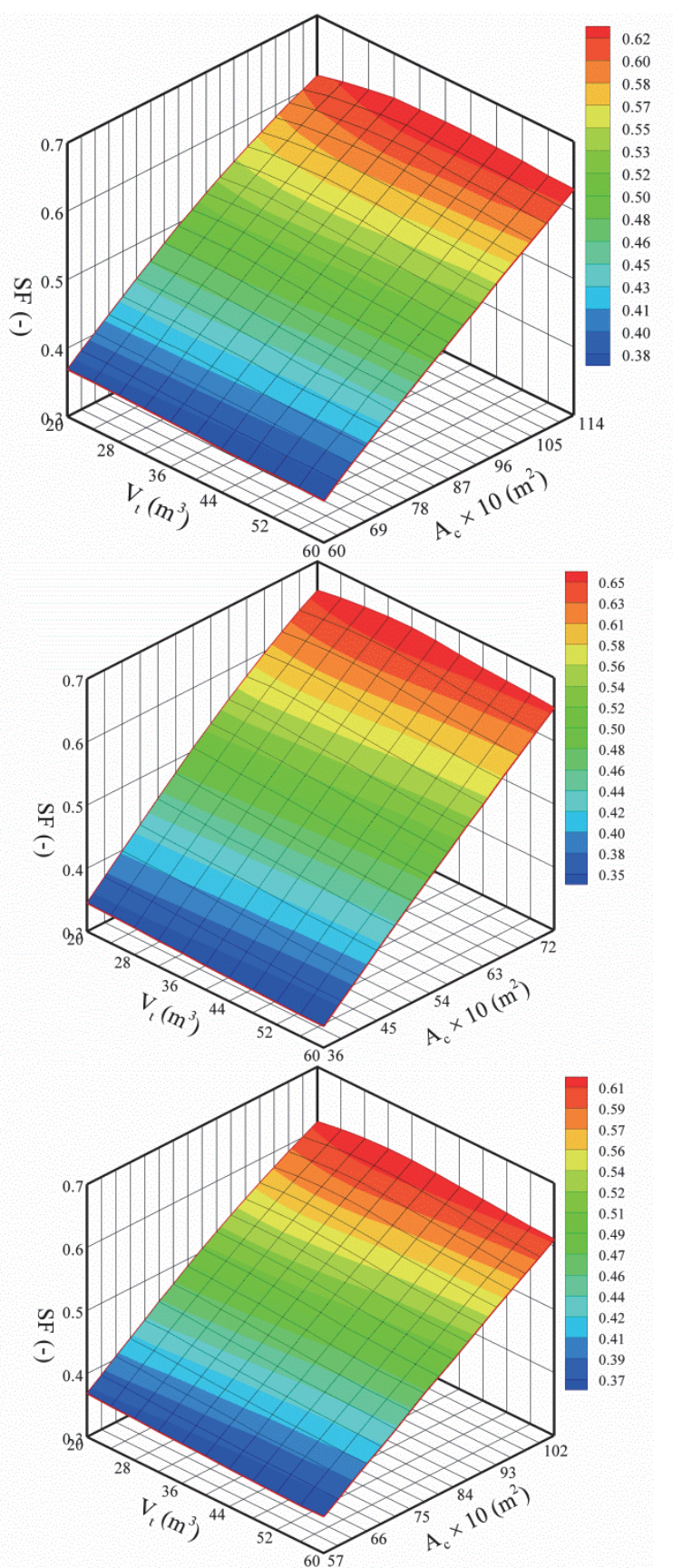

Fig. 6: Contour plots of the annual solar fraction $(S F)$ of the SHWP with respect to $A_{c}$ and $V_{t}$ at (a) Incheon, (b) Jeddah and (c) Changi airports.

\section{Results and discussions}

The parametric simulations have been performed to examine how the annual thermal, solar fraction $(S F)$ and solar thermal rating $(E)$, and economic, annualized life cycle saving $(A L C S)$ and payback period $(P B P)$, performances of the SHWPs are affected by the collector area $\left(A_{c}\right)$ and tank volume $\left(V_{t}\right)$ at the ASHRAE standard flow rate for $V_{l}=100 \mathrm{~m}^{3} /$ day. In this study, the plant configurations where the working fluid temperature does not exceed the boiling temperature are considered.

Fig. 6 shows the annual $S F$ of the SHWP with respect to $A_{c}$ and $V_{t}$. The $S F$ increases with increasing $A_{c}$ and decreasing $V_{t}$ at a smaller $A_{c}$. However, at a larger $A_{c}$ it
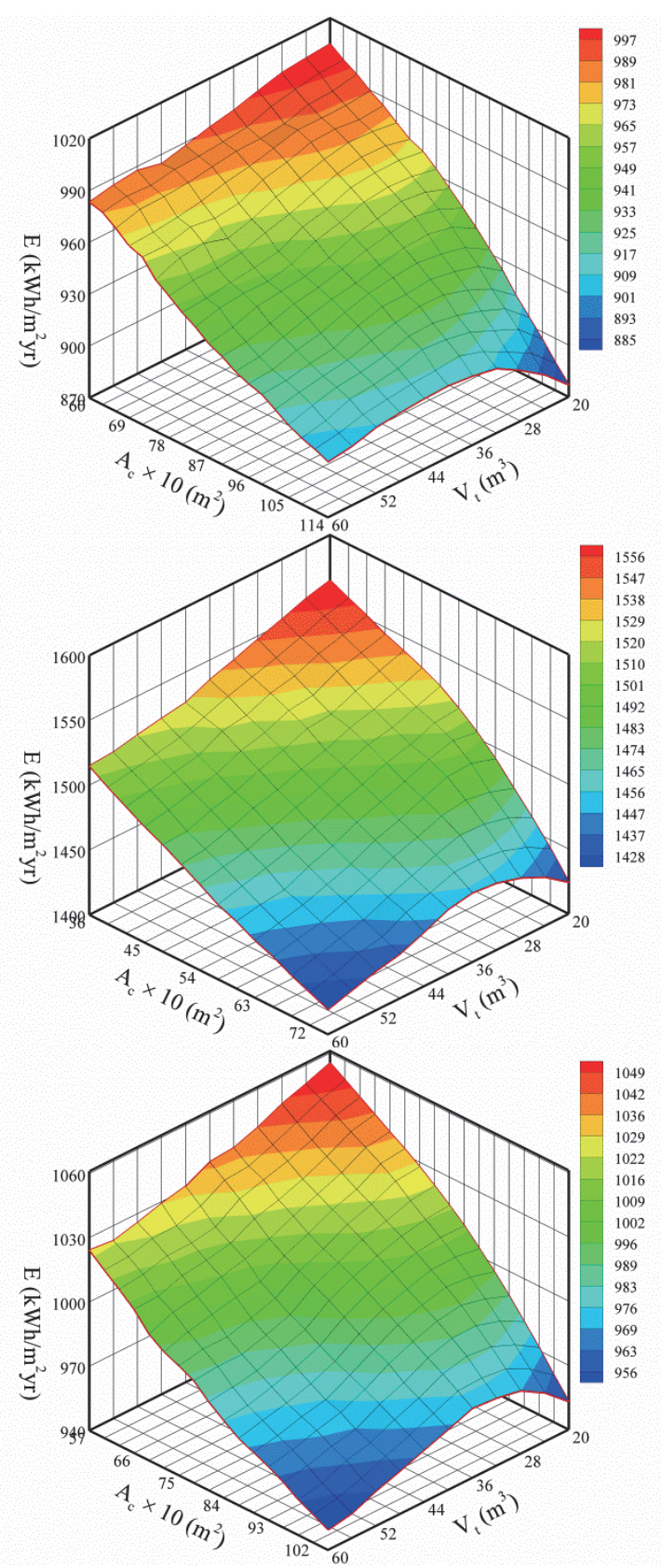

Fig. 7: Contour plots of the annual solar thermal rating (E) of the SHWP with respect to $A_{c}$ and $V_{t}$ at (a) Incheon, (b) Jeddah and (c) Changi airports. 
increases with the increase in $V_{t}$, and then decreases after attaining a maximum at some $V_{t}$. It is noted that at a lower $A_{c}$ the effect of $V_{t}$ on the $S F$ is negligibly small, while its effect becomes large at a higher $A_{c}$. The maximum $S F$ s of the SHWPs at Incheon, Jeddah and Changi airports are $0.636\left(A_{c}=1140 \mathrm{~m}^{2}, V_{t}=40 \mathrm{~m}^{3}\right)$, $0.668\left(A_{c}=750 \mathrm{~m}^{2}, V_{t}=36 \mathrm{~m}^{3}\right)$ and $0.626\left(A_{c}=1050 \mathrm{~m}^{2}\right.$, $\left.V_{\mathrm{t}}=36 \mathrm{~m}^{3}\right)$, respectively.

In contrast, the annual $E$ increases with a decrease in $A_{c}$ at fixed $V_{t}$, as presented in Fig. 7. The increase in $E$ with decreasing $A_{c}$ becomes larger as $V_{t}$ decreases below about $40 \mathrm{~m}^{3}$. It is because $S F$ at the larger $A_{c}$ decreases greatly with decreasing $V_{t}$. The maximum $E \mathrm{~s}$ of SHWPs at each airport are $1005 \mathrm{kWh} / \mathrm{m}^{2} \mathrm{yr}\left(A_{c}=600 \mathrm{~m}^{2}, V_{t}=20\right.$

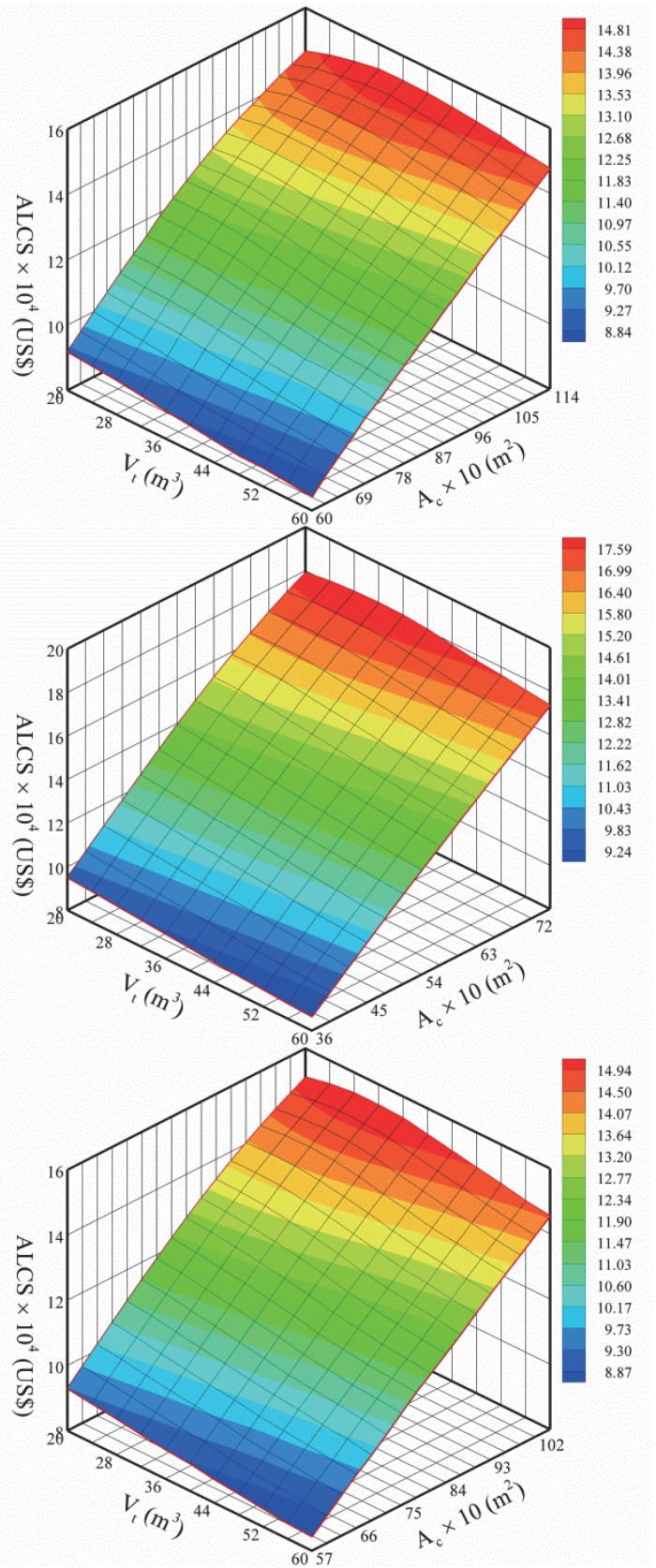

Fig. 8: Contour plots of the annualized life cycle saving (ALCS) of the SHWP with respect to $A_{c}$ and $V_{t}$ at (a) Incheon, (b) Jeddah and (c) Changi airports. $\left.\mathrm{m}^{3}\right), 1565 \mathrm{kWh} / \mathrm{m}^{2} \mathrm{yr}\left(A_{c}=360 \mathrm{~m}^{2}, V_{t}=20 \mathrm{~m}^{3}\right)$ and 1056 $\mathrm{kWh} / \mathrm{m}^{2} \mathrm{yr}\left(A_{c}=570 \mathrm{~m}^{2}, V_{t}=20 \mathrm{~m}^{3}\right)$, respectively.

The ALCSs of SHWPs with respect to $A_{c}$ and $V_{t}$ are shown in Fig. 8. With increasing $A_{c}$, an increased $A L C S$ can be achieved until a maximum at some $A_{c}$ for each $V_{t}$ is reached. However, the $A L C S$ will decrease with further increase in $A_{c}$, which causes higher fuel savings, but the plant cost increases excessively, forcing the $A L C S$ to decrease. The effect of $V_{t}$ on the $A L C S$ is almost similar to that on the $S F$. The maximum $A L C S$ s of SHWPs are $152358 \mathrm{US} \$\left(A_{c}=1140 \mathrm{~m}^{2}, V_{t}=36 \mathrm{~m}^{3}\right), 181848 \mathrm{US} \$\left(A_{c}\right.$ $\left.=750 \mathrm{~m}^{2}, V_{t}=32 \mathrm{~m}^{3}\right)$ and $153695 \mathrm{US} \$\left(A_{c}=1050 \mathrm{~m}^{2}, V_{t}\right.$ $=28 \mathrm{~m}^{3}$ ), respectively, at each airport.

As shown in Fig. 9, the $P B P$ decreases with the increase
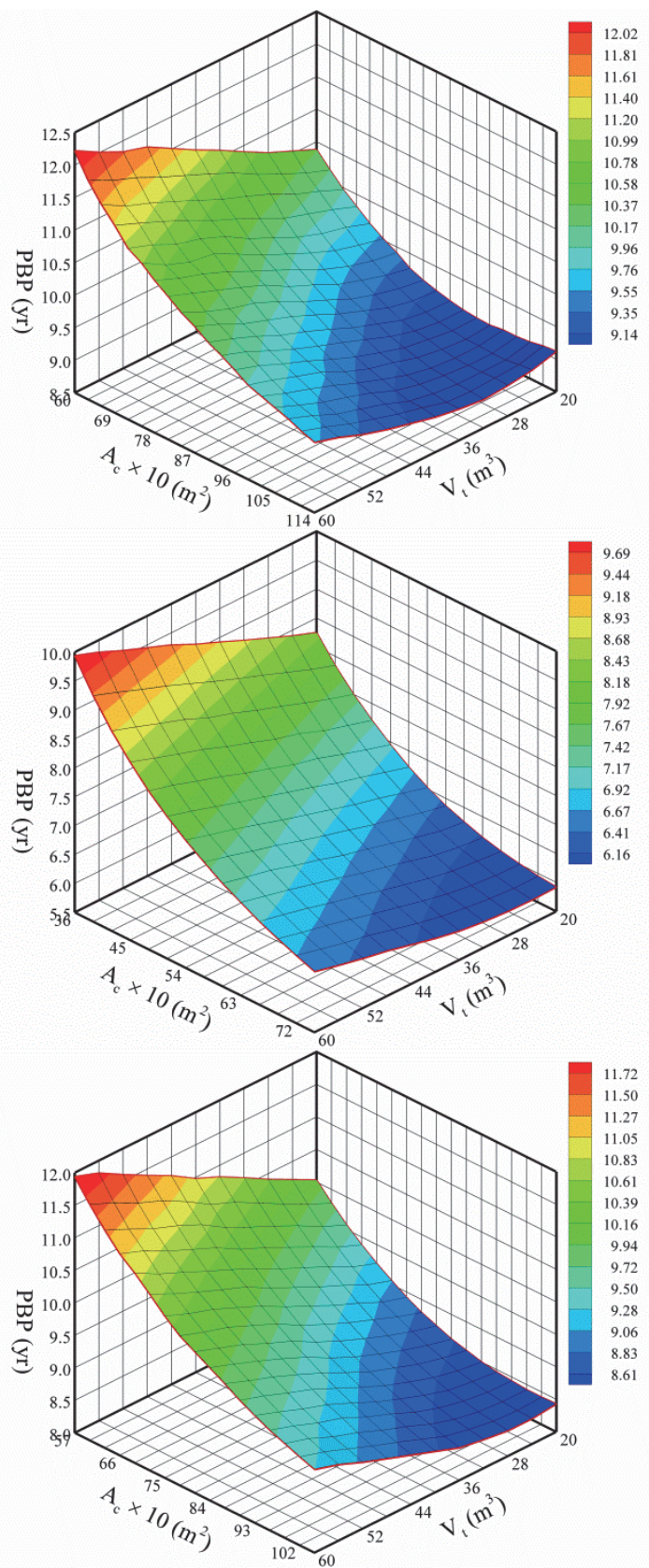

Fig. 9: Contour plots of the payback period $(P B P)$ of the SHWP with respect to $A_{c}$ and $V_{t}$ at (a) Incheon, (b) Jeddah and (c) Changi airports. 
in $A_{c}$ regardless of $V_{t}$, since the auxiliary fuel savings are far greater than the increase in cost due to increased $A_{c}$. As shown at a smaller $V_{t}$, for further increase in $A_{c}$ the $P B P$ increases because the increase in collector cost is higher than the savings on fuel. The $A_{c}$ corresponding to this minimum $P B P$ is the optimum $A_{c}$ with maximum fuel savings. At $A_{c} \mathrm{~s}$ below $930 \mathrm{~m}^{2}, 750 \mathrm{~m}^{2}$ and $1020 \mathrm{~m}^{2}$, respectively, for each airport the $P B P$ decreases with decreasing $V_{t}$, while above aforementioned $A_{c} \mathrm{~s}$ it has a minimum at some $V_{t}$ for each $A_{c}$. The minimum $P B P \mathrm{~s}$ of SHWPs at each airport are 8.94 years $\left(A_{c}=1140 \mathrm{~m}^{2}, V_{t}=\right.$ $\left.32 \mathrm{~m}^{3}\right), 5.91$ years $\left(A_{c}=750 \mathrm{~m}^{2}, V_{t}=24 \mathrm{~m}^{3}\right)$ and 8.39 years $\left(A_{c}=1050 \mathrm{~m}^{2}, V_{t}=28 \mathrm{~m}^{3}\right)$, respectively.

\section{Conclusions}

In this study, the thermal performance and cost effectiveness of active-indirect SHWPs at Incheon (Korea), Jeddah (Saudi Arabia) and Changi (Singapore) international airports are investigated and compared. The long-term performances of SHWPs with various collector areas and storage tank volumes at the ASHRAE standard flow rate have been examined and are reported in terms of the annual solar fraction, solar thermal rating, as well as the capital payback period and annualized life cycle savings. Then, the SHWPs that supply water at $65^{\circ} \mathrm{C}$ to a flight kitchen are parametrically optimized for the economic benefits for an average daily energy demand.

For the energy demand of $100 \mathrm{~m}^{3} /$ day, the maximum solar fractions of the SHWPs at Incheon, Jeddah and Changi airports are 0.636 with $A_{c}=1140 \mathrm{~m}^{2}$ and $V_{t}=40$ $\mathrm{m}^{3}, 0.668$ with $A_{c}=750 \mathrm{~m}^{2}$ and $V_{t}=36 \mathrm{~m}^{3}$ and 0.626 with $A_{c}=1050 \mathrm{~m}^{2}$ and $V_{t}=36 \mathrm{~m}^{3}$, respectively. The minimum payback periods of SHWPs at each airport are 8.94 years with $A_{c}=1140 \mathrm{~m}^{2}$ and $V_{t}=32 \mathrm{~m}^{3}, 5.91$ years with $A_{c}=750 \mathrm{~m}^{2}$ and $V_{t}=24 \mathrm{~m}^{3}$ and 8.39 years with $A_{c}$ $=1050 \mathrm{~m}^{2}$ and $V_{t}=28 \mathrm{~m}^{3}$, respectively.

\section{Nomenclature}

$A_{a} \quad$ aperture area per collector $\left(\mathrm{m}^{2}\right)$

$A_{c} \quad$ total collector area $\left(\mathrm{m}^{2}\right)$

$A_{c s} \quad$ cross sectional area of the tank $\left(\mathrm{m}^{2}\right)$

$A_{i} \quad$ anisotropy index

$A_{l} \quad$ lateral area of control volume $\left(\mathrm{m}^{2}\right)$

$c_{1} \quad$ global heat loss coefficient $\left(\mathrm{W} / \mathrm{m}^{2{ }^{\circ}} \mathrm{C}\right)$

$c_{2}$ temperature dependence of global heat loss coefficient $\left(\mathrm{W} / \mathrm{m}^{2 \circ} \mathrm{C}^{2}\right)$

$c_{3} \quad$ effective thermal capacity $\left(\mathrm{kJ} / \mathrm{m}^{2 \circ} \mathrm{C}\right)$

$c_{p} \quad$ mean specific heat capacity $\left(\mathrm{kJ} / \mathrm{kg}^{\circ} \mathrm{C}\right)$

$C_{B} \quad$ boiler cost coefficient (US\$)

$C_{c} \quad$ fluid heat capacity rate in primary circuit $\left(\mathrm{W} /{ }^{\circ} \mathrm{C}\right)$

$C_{C} \quad$ collector cost coefficient (US $\$ / \mathrm{m}^{2}$ )

$C_{D} \quad$ collector area dependent cost (US $\left.\$ / \mathrm{m}^{2}\right)$

$C_{F} \quad$ fuel cost coefficient (US $\$ / \mathrm{kWh}$ )

$C_{h} \quad$ fluid heat capacity rate in secondary circuit $\left(\mathrm{W} /{ }^{\circ} \mathrm{C}\right)$
$C_{I}$

$C_{I C} \quad$ instrumentation and control cost coefficient $\left(\mathrm{US} \$ / \mathrm{m}^{2}\right)$

$C_{H X} \quad$ heat exchanger cost coefficient (US $\left.\$ / \mathrm{m}^{2}\right)$

$C_{\min } \quad$ minimum heat capacity rate $\left(\mathrm{W} /{ }^{\circ} \mathrm{C}\right)$

$C_{P S} \quad$ pump and support structure cost coefficient (US\$ $/ \mathrm{m}^{2}$ )

$C_{R F} \quad$ capital recovery factor $(1 / \mathrm{y})$

$C_{S} \quad$ total cost of plant (US\$)

$C_{\mathrm{T}} \quad$ storage tank cost coefficient (US $\$ / \mathrm{m}^{3}$ )

$C^{*} \quad$ dimensionless heat capacity rate ratio

$e \quad$ fuel inflation rate $(\%)$

$f$ modulating factor

$F \quad$ control function

G mass flow rate per unit area of collector $\left(\mathrm{kg} / \mathrm{m}^{2} \mathrm{~s}\right)$

$G_{b} \quad$ monthly average hourly beam irradiance on a tilted plane $\left(\mathrm{W} / \mathrm{m}^{2}\right)$

$G_{d} \quad$ monthly average hourly diffuse irradiance on a tilted plane $\left(\mathrm{W} / \mathrm{m}^{2}\right)$

$G_{T} \quad$ monthly average hourly global irradiance on a tilted plane $\left(\mathrm{W} / \mathrm{m}^{2}\right)$

$h$

$H / D$

$i$

$i^{\prime}$

$i^{\prime}$

$i^{\prime \prime}$

$I_{b}$

$I_{d}$

$I_{d} \quad$ monthly average hourly diffuse irradiation on a horizontal plane $\left(\mathrm{J} / \mathrm{m}^{2}\right)$

$I_{h} \quad$ monthly average hourly global irradiation on a horizontal plane $\left(\mathrm{J} / \mathrm{m}^{2}\right)$

$I_{o} \quad$ monthly average hourly extraterrestrial irradiation on a horizontal plane $\left(\mathrm{J} / \mathrm{m}^{2}\right)$

$I_{T} \quad$ monthly average hourly global irradiation on a tilted plane $\left(\mathrm{J} / \mathrm{m}^{2}\right)$

inflation rate $(\%)$

$k \quad$ thermal conductivity of water $\left(\mathrm{W} / \mathrm{m}^{\circ} \mathrm{C}\right)$

$K_{\theta b} \quad$ beam radiation incidence angle modifier

$K_{\theta d}$

LMTD

$\dot{m}_{l}$

$\dot{m}_{p}$

$\dot{m}_{r}$

$\dot{m}_{s}$

$\dot{m}_{t}$ diffuse radiation incidence angle modifier logarithmic mean temperature difference $\left({ }^{\circ} \mathrm{C}\right)$ desired load mass flow rate $(\mathrm{kg} / \mathrm{s})$ mass flow rate in primary circuit, $A_{c} G(\mathrm{~kg} / \mathrm{s})$ makeup water mass flow rate $(\mathrm{kg} / \mathrm{s})$ mass flow rate in secondary circuit, $A_{c} G(\mathrm{~kg} / \mathrm{s})$ mass flow rate from storage to load $(\mathrm{kg} / \mathrm{s})$ life cycle of plant (yrs) auxiliary energy required (W) auxiliary energy required over a year $(\mathrm{J})$ desired hot water load over a year $(\mathrm{J})$ load met by solar energy (W) load met by solar energy over a year $(\mathrm{J})$ ratio of beam radiation on a tilted plane to that on the horizontal plane

$T_{a} \quad$ ambient temperature $\left({ }^{\circ} \mathrm{C}\right)$

$T_{c} \quad$ fluid temperature in primary circuit $\left({ }^{\circ} \mathrm{C}\right)$ 
$T_{h} \quad$ fluid temperature in secondary circuit $\left({ }^{\circ} \mathrm{C}\right)$

$T_{l} \quad$ desired load temperature $\left({ }^{\circ} \mathrm{C}\right)$

$T_{m} \quad$ mean fluid temperature $\left({ }^{\circ} \mathrm{C}\right)$

$T_{r} \quad$ makeup water temperature $\left({ }^{\circ} \mathrm{C}\right)$

$T_{t} \quad$ storage temperature $\left({ }^{\circ} \mathrm{C}\right)$

$U_{t} \quad$ overall heat transfer coefficient of the storage tank $\left(\mathrm{W} / \mathrm{m}^{2 \circ} \mathrm{C}\right)$

$U_{H X} \quad$ overall heat transfer coefficient of the plate heat exchanger $\left(\mathrm{W} / \mathrm{m}^{2 \mathrm{o}} \mathrm{C}\right)$

$V_{l} \quad$ daily hot water load $\left(\mathrm{m}^{3} /\right.$ day $)$

$V_{t} \quad$ storage tank volume $\left(\mathrm{m}^{3}\right)$

\section{Greek symbols}

$\beta \quad$ slope $\left({ }^{\circ}\right)$

$\varepsilon \quad$ effectiveness

$\eta \quad$ collector efficiency

$\eta_{\text {aux }} \quad$ boiler efficiency

$\eta_{0} \quad$ optical efficiency

$\theta \quad$ incidence angle $\left({ }^{\circ}\right)$

$\theta_{z} \quad$ zenith angle $\left({ }^{\circ}\right)$

$\mu \quad$ dynamic viscosity $(\mathrm{kg} / \mathrm{ms})$

$\rho \quad$ fluid density $\left(\mathrm{kg} / \mathrm{m}^{3}\right)$

$\phi \quad$ latitude $\left({ }^{\circ}\right)$, utilizability

\section{Abbreviations}

ALCS annualized life cost saving

CGM conjugate gradient method

HDKR Hay-Davies-Klucher-Reindl

NTU number of transfer units

PBP payback period

SF solar fraction

SHWP solar hot water plant

SMS Singapore meteorological service

SSE surface meteorology and solar energy

\section{Acknowledgments}

This research was supported by Basic Science Research Program through the National Research Foundation of Korea (NRF) funded by the Ministry of Education (NRF-2014R1A1A2058979).

\section{References}

1) H. C. Hottel, A. Whillier, "Evaluation of flat-plate collector performance", Trans. the Conference on the Use of Solar Energy 2, University of Arizona Press, 74-104 (1958).

2) B. Y. H. Liu, R. C. Jordan, "A rational procedure for predicting the long-term average performance of flat-plate solar-energy collectors", Solar Energy, 7, 53-74 (1963).

3) S. A. Klein, "Calculation of flat-plate collector utilizability", Solar Energy, 21, 393-402 (1978).

4) S. A. Klein, W. A. Beckman, J. A. Duffie, "A design procedure for solar heating systems", Solar Energy, 18, 113-127 (1976).

5) S. A. Klein, W. A. Beckman, "A general design method for closed-loop solar energy systems", Solar Energy, 22, 269-282 (1979).

6) V. G. Chant, R. Håkansson, "The MINSUN simulation and optimisation program", Application and user's guide, IEA SH\&C Task VII, Ottawa (1985)

7) P. D. Lund, "A general design methodology for seasonal storage solar systems", Solar Energy, 42, 235-251 (1989).

8) S. A. Klein, P. I. Cooper, T. L. Freeman, D. M. Beekman, W. A. Beckman, J. A. Duffie, "A method of simulation of solar processes and its application", Solar Energy, 17, 29-37 (1975).

9) J. F. Orgill, K. G. T. Hollands, "WATSUN - solar heating simulation and economic evaluation program - user's manual", University of Waterloo, (1976).

10)Y.-D. Kim, K. Thu, H. K. Bhatia, C. S. Bhatia, K. C. $\mathrm{Ng}$, "Thermal analysis and performance optimization of a solar hot water plant with economic evaluation", Solar Energy, 86, 1378-1395 (2012).

11) Y.-D. Kim, K. Thu, N. Ghaffour, K. C. Ng, "Performance investigation of a solar-assisted direct contact membrane distillation system", Journal of Membrane Science, 427, 345-364 (2013).

12)P. W. Stackhouse, C. H. Whitlock, "Surface meteorology and Solar Energy (SSE) rel. 6.0", NASA, http://eosweb.larc.nasa.gov/sse/.

13)M. Collares-Pereira, A. Rabl, "The average distribution of solar radiation-correlations between diffuse and hemispherical and between daily and hourly insolation values", Solar Energy, 22, 155-164 (1979).

14)B. Y. H. Liu, R. C. Jordan, "The interrelationship and characteristic distribution of direct, diffuse and total solar radiation", Solar Energy, 4, 1-19 (1979).

15)J. E. Hay, J. A. Davies, "Calculation of the solar radiation incident on an inclined surface", Proc. 1st Canadian Solar Radiation Data Workshop, Toronto, 59-72, 1980.

16)R. C. Temps, K. L. Coulson, "Solar radiation incident 
upon slopes of different orientations", Solar Energy, 19, 179-184 (1977).

17)T. M. Klucher, "Evaluation of models to predict insolation on tilted surfaces", Solar Energy, 23, 111114 (1979).

18)D. T. Reindl, W. A. Beckman, J. A. Duffie, "Evaluation of hourly tilted surface radiation models", Solar Energy, 45, 9-17 (1990).

19) Weather Underground, http://www.wunderground.com/ (2010).

20)Y.-D. Kim, W.-S. Kim, "Re-evaluation and modeling of a commercial diesel oxidation catalyst", Industrial Engineering Chemistry Research, 48, 6579-6590 (2009).

21)A. Rabl, Active Solar Collectors and their Applications, Oxford University Press, Oxford (1985).

22)EN 12975-2, "Thermal solar systems and components - Solar collectors - Part 2: Test Methods", Section 6.1. European Standard (2006).

23) W. R. McIntire, "Factored approximations for biaxial incident angle modifiers", Solar Energy, 29, 315-322 (1982).

24)R. P. Singh, D. R. Heldman, Introduction to Food Engineering, Elsevier Inc., London (2008).

25)M. N. A. Hawlader, K. C. Ng, T. T. Chandratilleke, D. Sharma, H. L. Kelvin Koay, "Economic evaluation of a solar water heating system", Energy Conversion Management, 27, 197-204 (1987). 